\title{
Comparing international and South African work-based assessment of medical interns' practice
}

\author{
K L Naidoo, ${ }^{1,2}$ MB ChB, DCH, FCPaed; J van Wyk, ${ }^{3}$ BSc Ed, BEd, MEd, PhD; M Adhikari, ${ }^{2}$ MB ChB, FCPaed, PhD \\ ${ }^{1}$ King Edward VIII Hospital, KwaZulu-Natal Department of Health, Durban, South Africa \\ ${ }^{2}$ Department of Paediatrics and Child Health, Nelson R Mandela School of Medicine, University of KwaZulu-Natal, Durban, South Africa \\ ${ }^{3}$ Department of Clinical and Professional Practice, Nelson R Mandela School of Medicine, University of KwaZulu-Natal, Durban, South Africa
}

Corresponding author: KNaidoo (naidook9@ukzn.ac.za)

\begin{abstract}
Background. Resource constraints and a high disease burden impact on the work-based assessment (WBA) of medical interns in South Africa (SA). Objectives. To review the use of workplace-based assessment frameworks in intern practice in SA and to compare these with international practices. Methods. A systematic review using a thematic analysis was performed to analyse 97 articles selected from an initial scoping of 360 sources of evidence on WBA in internship between 2000 and 2017. This process informed a synthesis of descriptive and analytic themes related to competency-based assessment practices relevant to internship in SA.

Results. There was an overall dearth of studies on assessment of medical interns in lower-middle-income countries (LMICs). The context in which the assessment of interns in SA occurs has many challenges related to resources, workload and supervision. SA intern assessment is largely focused on core clinical competency, and this occurs without using competency-based frameworks. This focus was reflected in the finding that most studies in SA have dealt with the assessment of core procedural skills related to acute clinical care, while the assessment of non-clinical competencies and non-procedural skills was poorly addressed. Self-assessment by interns was the predominant strategy used in the SA context. The review revealed limitations in the use of multiple assessment strategies and direct observation in the local context, in contrast to practices in most high-income countries.

Conclusions. A shift in focus to assess both procedural and non-procedural skills within a competency-based framework is advocated for SA internship, together with the use of multiple assessment tools and strategies that rely on direct observation of performance.
\end{abstract}

Afr J Health Professions Educ 2018;10(1):44-49. DOI:10.7196/AJHPE.2018.v10i1.955

Internship following graduation is an essential period for junior doctors to develop their skills and apply their knowledge in the context of the local health system. Newly qualified medical doctors in South Africa (SA) enter a supervised 2-year internship period requiring learning and service delivery to occur concurrently in a work-based setting. Work-based assessment (WBA) during internship is integral to identifying underperformance and to informing decisions regarding certification for independent, unsupervised practice. ${ }^{[1]} \mathrm{WBA}$ is a complex process that should include the assessment of multiple competencies using validated methods and tools that accurately reflect performance. The assessment process aims to ensure that doctors perform as competent, ethical practitioners who have 'globally connected, locally responsive attributes that are population and patient-centred. ${ }^{[2]}$ Research into effective WBA practices has led to advances in understanding the optimal ways to assess interns. ${ }^{[3]}$ Many of these innovations in WBA have, however, not yet been translated into practice in many lower-middleincome countries (LMICs) such as SA. ${ }^{[4]}$

Internship training in SA, as in many other LMICs, occurs within a resource-constrained workplace setting where high patient-doctor ratios are the norm. ${ }^{[2]}$ The high rate of needlestick injuries in an HIV-burdened context, coupled with long working hours, has resulted in high levels of stress and burnout among interns in SA. ${ }^{[5]}$ Additional factors impacting negatively on intern training include poor institutional leadership and an inability to recruit, retain and develop appropriate staff. ${ }^{[6,7]}$ There is an increasing number of reports of overburdened and inadequately experienced supervisors, which also influences the quality of internship training across institutions in SA. ${ }^{[8,9]}$ The concurrent impact of inadequate supervision within poor working conditions has raised concerns about the quality of assessments of interns in this context. ${ }^{[5,8]}$

The Health Professionals Council of SA (HPCSA) is the regulatory body responsible for the accreditation of institutions, supervisors, curricula and intern-assessment practice. ${ }^{[1]}$ The HPCSA undertakes biannual accreditation visits to each institution to evaluate and ensure adherence to the mandated requirements for adequate training. ${ }^{[1]}$ While a graduate competency framework derived from the Royal College of Physicians and Surgeons of Canada physician competency framework (CanMEDS) has been adopted by most undergraduate and many postgraduate medical training programmes in SA, this has not been rigorously applied to the internship period. ${ }^{[10]}$

WBA in internship in SA is based around a logbook that includes discipline-specific competencies focusing on procedural skills and some non-procedural skills, including medical ethics. Checklists that rely on self-assessment by interns and inputs from their supervisors with regard to performance are included in the logbook for each discipline. ${ }^{[1]}$

This study was conducted to analyse assessment practices within a competency-based framework in a resource-limited environment. This process can help to identify weaknesses, benchmark practices and inform decisions, in improving the assessment of interns in SA and in other LMICs. 


\section{Methodology}

The literature review used a thematic analysis to synthesise findings on assessment practices within a competency-based framework among interns in SA, compared with international practice. Thematic analysis is often used to analyse data in primary qualitative research and can be used in systematic reviews to bring together and integrate the findings of multiple qualitative studies. ${ }^{[1]} \mathrm{A}$ thematic analysis was undertaken to review the studies, which included many diverse approaches to research. The aim of this research synthesis was to identify and highlight key concepts from literature sources and to recognise and compare the use of the same concepts in other studies. ${ }^{[12]}$

\section{Search strategy}

The initial scoping of the literature involved searches on electronic databases by the primary author and an assistant. The databases searched included: EBSCO HOST; Medline; PubMed; ERIC (Education Resources Information Centre); SABINET (SA Bibliographic Information Network) and Education Source. The terminology to describe a medical intern, i.e. a doctor in the first 2 years following undergraduate medical qualification, varies greatly. The terms commonly used include 'medical intern'; 'foundation year doctor'; 'pre-registration house officer' and 'junior doctor'. In all databases searched, these terms were used as the primary search terms. The key words 'assessment', 'assessment tools', 'competency' and 'competency framework' were used in conjunction with the primary search terms. In addition to the articles obtained through various databases, articles were selected based on manual searches of references cited in key articles. Policy reviews, reports relating to assessment and evaluation of national intern programmes, stakeholder analyses, theses and conference proceedings were included in the secondary search. Fig. 1 indicates the process followed in the systematic literature review.

English-language articles published between 2000 and 2017 were included for review. The last search was conducted at the end of January 2017. The articles selected for inclusion focused only on the WBA of junior doctors in their first 2 years post qualification (interns). Literature that included undergraduate medical students was excluded. Articles describing the assessment of first-year residents in specialty programmes in the USA were included, while those that focused on specialty programmes whose participants were in the later years of specialisation (secondyear residents onwards) were excluded.

\section{Quality criteria}

Assessing the quality of the largely qualitative research studies that were identified was necessary to avoid drawing unreliable conclusions. ${ }^{[11]}$ In our review, we assessed studies according to seven broad criteria: ${ }^{[13,14]}$ the relevance of the study to the review question; the appropriateness of study design; transferability of the conclusions drawn; the use of context to enable comparability of the findings to interns in SA; data collection; analysis; and finally, an account of reflexivity, in terms of recognising personal biases. ${ }^{[14]}$

\section{Data extraction}

All articles identified from the initial scoping of the literature were reviewed by the main author using the inclusion criteria stipulated.* Those studies identified after this process were subjected to a quality assessment, as indicated. Those studies that were identified following the quality assessment were scanned for key concepts, which were inductively coded and tabulated.

A second independent investigator, a professional health educator, then reviewed the inductive codes to ensure concordance with the primary sources. The individually derived codes were subsequently discussed between the researchers to reach consensus on the final descriptive themes.

\section{Data synthesis}

The synthesis took the form of three stages: line-by-line coding of the findings of primary studies; organisation of these 'free codes' into related areas to construct descriptive themes; and the development of analytical themes. A multidisciplinary review team consisting of the main author (an intern supervisor and clinician), the second author (the professional health educationist) and the third author (an academic experienced in postgraduate training) reviewed the data obtained to ensure its relevance and robustness in fulfilling the objectives of the review. The analytical themes were refined through a cyclical process with the primary author developing the first draft of inductive codes and two co-authors contributing to the refining and identification of the final themes. The final themes, chosen by consensus, were sufficiently comprehensive to describe the categories and to meet the primary objective of the review. ${ }^{[11,12]}$

\section{Results}

The results from the literature searches indicated that the number and quality of research evidence on WBA during internship differed significantly between international and SA sources. A total of

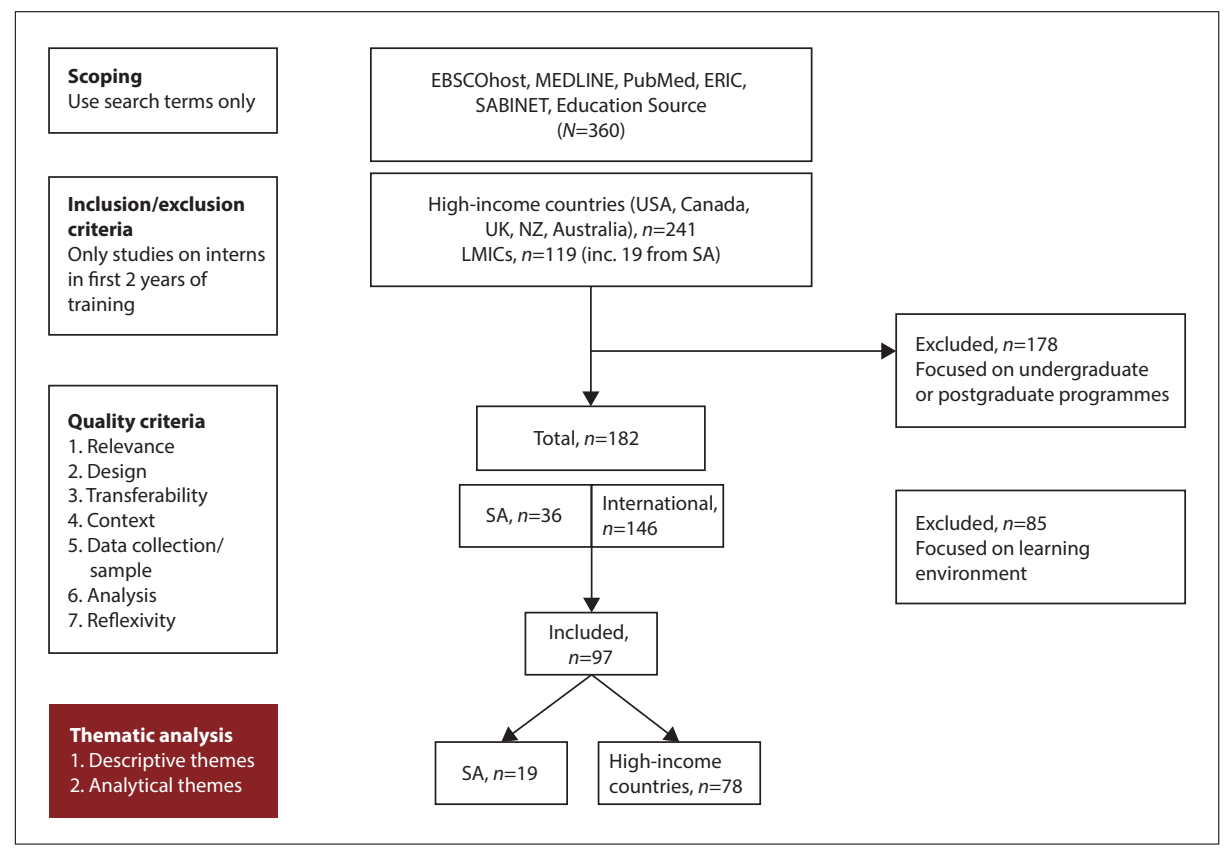

Fig. 1. Inclusion and exclusion criteria. (SABINET = South African Bibliographic Information Network; ERIC = Education Resources Information Centre; $N Z=$ New Zealand; LMICs = lower-middle-income countries; inc. = including; $S A=$ South Africa.) 
$67 \%$ percent of the initial 360 articles sourced from the primary searches were from high-income countries, i.e. the UK, North America (USA and Canada), Western Europe, Australia and New Zealand.

Using the inclusion and exclusion criteria - selecting only studies involving newly qualified doctors in their first 2 years following graduation (interns) -182 articles were selected. Of these, 146 were from high-income countries, and 36 from SA. An application of the quality criteria revealed a large number of studies that did not meet the criteria, as they were not relevant to the research question. ${ }^{[13,14]}$ As indicated in Fig. 1, many studies identified in our search on assessment among interns dealt largely with environmental factors, and not assessment within a competency framework.

Only 19 SA articles had a primary focus on WBA in interns, while 78 articles from high-income countries focused on the objectives of the review.
Ninety-seven articles were thus finally included for analysis to identify definitive themes (Fig. 1).

The review aimed to extract and synthesise findings relating to the use of competency-based assessment frameworks among interns in SA. There was a paucity of studies on competency-based assessment among interns in SA in comparison with the studies from high-income countries. The aim of the study was therefore to compare and report on similarities and differences in the WBA of medical interns across the two contexts.

Tables $1-4$ depict the major descriptive themes identified from the inductive codes, which were derived from the primary sources of literature, and the four analytical themes developed. These themes are lack of competency-based frameworks in accrediting interns in SA', 'emphasis on assessing only clinical procedural skills instead of both clinical and

Table 1. Analytical theme 1: Lack of competency-based frameworks

\begin{tabular}{lll}
\hline Inductive codes from primary sources & Major descriptive themes & Analytical themes \\
\hline $\begin{array}{l}\text { 1. Defining competency-based systems } \\
\text { 2. Reasons for shifting towards a competency-based system }\end{array}$ & & \\
$\begin{array}{l}\text { 3. Validation of competency tools using factor analysis and other methods } \\
\text { 4. Defining specific competencies required by junior doctors }\end{array}$ & $\begin{array}{l}\text { The use of a competency-based } \\
\text { framework }\end{array}$ & $\begin{array}{l}\text { Lack of competency-based } \\
\text { frameworks }\end{array}$ \\
$\begin{array}{l}\text { 5. Limitations in competency-based assessments } \\
\text { 6. A shift to the use of entrustable professional activities and milestones }\end{array}$ & & \\
7. Rates of underperformance & Recognition of underperformance & \\
8. Factors affecting underperformance among interns & \\
9. Innovative and new methods of assessing 'at-risk' interns &
\end{tabular}

Table 2. Analytical theme 2: Emphasis on assessing clinical procedural skills

\begin{tabular}{lcc}
\hline Inductive codes from primary sources & Major descriptive themes & Analytical themes \\
\hline 1. Procedural skills assessed: & & \\
- Resuscitation & & \\
- Obstetric and anaesthetic skills & Type of skills being assessed & Emphasis on assessing clinical \\
- Paediatrics & & procedural skills \\
- Surgical and related disciplines skills & & \\
2. Non-procedural skills: & & \\
- Prescribing skills & & \\
- Rocumentation of clinical events and procedures & & \\
- Mental-state examinations &
\end{tabular}

Table 3. Analytical theme 3: Self-assessment instead of direct observed assessment

\begin{tabular}{lll}
\hline Inductive codes from primary sources & Major descriptive themes & Analytical themes \\
\hline - Evidence of the poor reliability of self-assessment tools & & Self-assessment instead of direct \\
- Poorly performing interns have poor ability in self -assessment & The use of self-assessment & \\
- Aggregate self-assessment valid for programme evaluation & & \\
- Phe use of log books or tick lists not a reliable tool for assessment & & \\
- Multisource feedback tools used successfully among interns & \\
- The use of mini-CEX (clinical evaluation exercise) & The use of directly observed \\
- The use of the mini-PAT (peer assessment tool) & \\
- The use of the DOPS (directly observed procedural skills) & \\
- The use of peer review tools &
\end{tabular}




\begin{tabular}{|c|c|c|}
\hline Inductive codes from primary sources & Major descriptive themes & Analytical themes \\
\hline $\begin{array}{l}\text { - Constant change as a norm of the intern working environment } \\
\text { - Disease burdens of LMICs } \\
\text { - Burnout } \\
\text { - Workload as an aggravating factor in internship } \\
\text { - Workhours in internship } \\
\text { - Reliability of resources in internship learning environment } \\
\text { - relevance of measuring intern preparedness }\end{array}$ & Challenges in the learning environment & \\
\hline $\begin{array}{l}\text { - Trends in preparedness across disciplines and institutions } \\
\text { - Factors influencing preparedness of interns } \\
\text { - Linkages of preparedness with undergraduate training }\end{array}$ & Preparedness & Impact of the learning environment \\
\hline $\begin{array}{l}\text { - Critical gaps in supervisor interaction } \\
\text { - Duration and engagement of supervision } \\
\text { - Quality of supervision } \\
\text { - Subjectivity of supervision } \\
\text { - Training of supervisors } \\
\text { - Support provided for supervisors }\end{array}$ & Supervisor interaction & \\
\hline $\begin{array}{l}\text { - Duration of feedback to interns } \\
\text { - Quality of feedback to interns } \\
\text { - Benefits of feedback during internship } \\
\text { LMICs = lower-middle-income countries. }\end{array}$ & Feedback & \\
\hline
\end{tabular}

non-procedural skills', 'use of self-assessment instead of direct observed assessment' and the 'influence of the learning environment on internship'.

\section{Discussion}

Clear differences were identified in various aspects of WBA between the international and SA settings. The first and most obvious difference was noticeable in the number of studies and research articles reporting on issues relating to WBA during internship. The second difference related to the dearth of studies conducted in the field of medical and health professions education in LMICs and in SA. The limited number of reported research projects in medical education from sub-Saharan African countries has been documented before. ${ }^{[15-17]}$ This review confirms the previous observation and confirms the discrepancy in literature relating to research on WBA among interns.

The review of the literature relating to WBA in high-income countries showed a clear focus on assessing the knowledge, skills and attitudes of interns by using a competency-based assessment framework. The two broad areas of competency focused on the assessment of core clinical skills and nonclinical competencies, including communication and professionalism. ${ }^{[18,19]}$ The analysis of the international literature also indicated a shift towards the use of 'entrustable professional activities (EPAs)' as a possible framework for measuring activities of trainees in specific workplace settings. The use of these 'concrete critical activities which infer the presence of multiple competencies help [s] bridge the gap between the theories of competencybased education and clinical practice. These EPAs should be 'independently executable, observable and measurable'; an example of such an activity is executing a patient handover. ${ }^{[21]}$

The concept of milestones, as introduced in best-evidence international practice, provides greater clarity and understanding of the incremental development of competencies in junior doctors over time. ${ }^{[20-22]}$

SA studies, however, did not report on the use of competency-based frameworks, EPAs or any other time-based indicators (milestones) to measure progress of interns in the work-based setting. ${ }^{[20]}$ The main focus in the SA literature was the assessment of core procedural skills in acute emergency and clinical situations. SA studies indicated the suboptimal performance of interns in paediatric resuscitation, obstetric practice, anaesthesia, orthopedics, intubation, circumcision and appendectomies..$^{[9,15,23,24]}$ The emphasis on procedural skills in acute emergencies possibly reflects the narrow interpretation of the role SA interns are expected to play within institutional hierarchical systems, and disregard for assessing their competence in knowledge, attitudes and non-clinical functions. This lack of studies on non-procedural skills in SA identifies clear gaps in the assessment methods of interns in SA. Gaps in the assessment of non-procedural skills such as prescribing medication, communication and mental-state examinations were also identified in a systematic review of non-technical skills in LMICs that highlighted the lack of tools to assess non-procedural skills. ${ }^{[16]}$ This gap indicates a need for SA to align intern training and assessment frameworks with undergraduate and postgraduate practice, which frame curricula and assessment practices within frameworks such as CanMEDS. ${ }^{[25]}$ The use and benefits of EPAs specific to each discipline may make the acceptance of their use for assessment, and the measuring of competencies, much easier. ${ }^{[19]}$

The literature from high-income countries reflected a trend away from relying on self-assessment as the sole means of determining intern performance. Self-assessment is shown to have a poor correlation with other modes of evaluation. ${ }^{[26-28]}$ Interns were unable to judge their own performance. ${ }^{[29]}$ The least-skilled intern seems to have the poorest ability to self-assess, which they are often unable to correct even with support. ${ }^{[26}$ 
Aggregated self-assessment was more useful for tracking cohorts and for programme evaluation. ${ }^{[30]}$

SA practice largely emphasises self-reported assessments of interns. ${ }^{[1]}$ Some SA studies have also indicated that poorly skilled interns were unduly optimistic about their own performance, ${ }^{[31]}$ and that interns' perceptions of competence were unrelated to the assessments by others of their performance. ${ }^{[32]}$ This may strengthen the argument for the use of multiple methods of assessment, instead of the reliance on self-assessment.

Innovations in WBA from developed countries feature the use and validation of tools that use direct observation. These tools, used either alone or in combination with other modes of assessment, are often centrally developed for a country or district and require significant human resources and administration. The use of Mini CEX (clinical evaluation exercise), mini PAT (peer assessment tool) and DOPS (directly observed procedural skills) systems was reported in the international literature, reflecting the use of multiple tools of assessment of interns in high-income countries. The 360-degree multisource feedback (MSF) assessment process was found to have robustness and feasibility in the first year of internship. ${ }^{[33]}$ MSF tools were well received and well aligned to the job, and improvements became evident owing to the use of the MSF strategy. ${ }^{[34]}$ The MSF process was regarded as a viable strategy to assess a large number of doctors. ${ }^{[35]}$

SA literature did not feature articles on the use of directly observed tools for WBA, reflecting a major gap in the reporting, validation and use of efficient assessment tools among interns. In SA it is likely that inclusion of all categories of staff, including middle-grade medical, allied health professionals and nursing staff, in assessments could promote integration, teamwork and the assessment of non-core skills such as communication and professionalism that is currently missing from the assessment system. The lack of multiple directly observed tools of assessment for interns in SA reflects the current status of assessment, the challenges and the shortage of sufficiently experienced supervisors. ${ }^{[7,8]}$

Various factors were documented in the literature to indicate the challenges faced by internship training in SA and other LMICs. This context is noted for having high workloads, resource limitations and inadequate supervisor support and training. The consequence of this constrained environment of suboptimal supervision is compromising of patient safety, especially due to poorly skilled and trained interns. International research among interns reflects on the assessment of practices to ensure that patient safety is prioritised. ${ }^{[36]}$ In SA hospitals, there is a lack of emphasis on assessing interns on practices that ensure patient safety, despite identification of the fact that their excessive workload and long work hours compromise patient care. ${ }^{[8,37]}$ Despite the challenges involved, proven innovations and developments in assessment processes from high-income countries need to be adapted and explored within the context of SA and LMICs to optimise the training of interns.

\section{Recommendations}

The WBA of interns in South Africa needs to adopt a broad competencybased framework that encompasses the assessment of knowledge, skills and attitudes. Linking internship with the graduate competency-based frameworks of undergraduate and postgraduate courses will assist in this.

Both procedural and non-procedural skills need to be assessed. Nonprocedural skills in internship, including skills in communication, prescribing, mental-state evaluations and documentation, among other 'soft skills', need to be given adequate place in the assessment of interns in SA.

There is a need to recognise the 'novice-to-expert' trajectory among interns over a 2-year period. The use of milestones should be incorporated within this framework, as well as the use of clearly defined disciplinespecific EPAs that can be easily measured to determine competencies.

Multiple tools of assessment need to be used that focus on direct observation as well as elements of self-assessment.

Intern assessment needs to include tools that focus on patient safety.

The MSF tool is practical, usable for large numbers and will enable teamwork. This process will enable an equitable emphasis on skills such as communication and professionalism, which are currently neglected.

Further research on the use of directly observed tools of assessment that assess all types of skills and competencies within a resource-challenged context needs to be done.

\section{Strengths and limitations}

Despite the differences in the quantity of studies emanating from LMICs as compared with high-income countries, this review attempted to identify significant differences in assessment practice and propose recommendations to improve WBA.

This review was restricted to articles published in English over the last 17 years. Literature included reports, guidelines theses, policy reviews and stakeholder analyses. Abstracts presented at conferences relating to the assessment of medical interns were not included for analysis, if they could not be found via an electronic database.

Studies of first-year residents in the US context were included whilst studies with defined internship periods elsewhere were focused on.

\section{Conclusions}

In $\mathrm{SA}$, the focus in WBA among interns is on assessing core procedural skills without a competency-based framework. This occurs to the detriment of assessing non-procedural skills and non-clinical competencies, and fails to consider milestones in this process. Self-assessment methodologies, which have proved to be inadequate in assessing interns, predominate in SA. The use of multiple methods of assessment for interns, including tools that incorporate direct observation, is being implemented in most highincome countries, and needs to be evaluated for use in SA. The use of MSF is proving efficient for large numbers of doctors. Many developments in WBA within high-income countries are relevant to the SA context, and their adaptation or adoption within a resource-constrained context should be explored to overcome gaps identified in intern training.

*The datasets extracted and analysed in this study are available from the corresponding author on reasonable request.

Acknowledgements. Mrs. Leora Sewnarain for assistance with typesetting and Ms Rani Moodley for assistance with the database searches.

Author contributions. KLN was responsible for study design, data collection, data analysis and drafting the manuscript. JVW was responsible for supervision of the entire project, study design and manuscript review. MA was responsible for supervision of the entire project and manuscript review.

Funding. MEPI funding: This publication was made possible by grant number 
R24TW008863 from the Office of the US Global AIDS Co-ordinator and the US Department of Health and Human Services, National Institutes of Health (NIH OAR and NIH ORWH). Its contents are solely the responsibility of the authors and do not necessarily represent the official views of the US government.

Conflicts of interest. None.

1. Medical and Dental Professions Board, Health Professions Council of South Africa. Handbook on Internship Training. Guidelines for Interns, Accredited Facilities and Health Authorities. Pretoria: HPCSA, 2016.

2. Frenk J, Chen L, Bhutta Z, et al. Health professionals for a new century: Transforming education to strengthen . Frenk J, Chen L, Bhutta Z, et al. Health professionals for a new century: Transforming education to strengthen
health systems in an interdependent world. Lancet 2010;376(9756):1923-1958. https://doi.org/10.1016/s0140health systems in

3. Norcini J, Burch V. Workplace-based assessment as an educational tool: AMEE Guide No. 31. Med Teach 2007;29(9-10):855-871. https://doi.org/10.1080/01421590701775453

4. Burch V. Portfolios for assessment and learning: Guide Supplement 45.1 - Viewpoint. Med Teach 2011;33(12):1029-1031. https://doi.org/10.3109/0142159x.2011.596589

5. Bateman C. System burning out our doctors - study. S Afr Med J 2012;102(7):593-594. https://doi.org/10.7196/ samj.6040

6. Ibeziako O, Chabikuli O, Olorunju S. Hospital reform and staff morale in South Africa: A case study of Dr Yusuf Dadoo Hospital. S Afr Fam Pract 2013;55(2):180-185. https://doi.org/10.1080/20786204.2013.10874330

7. Tumbo J, Sein NN. Determinants of effective medical intern training at a training hospital in North West Province, South Africa Afr J Health Professions Ecuc 2012;4(1):10-14. https://doi.org/10.7196/ajhpe. 100

8. Bola S, Trollip E, Parkinson F. The state of South African internships: A national survey against HPCSA goidelines. S Afr Med J 2015;105(7):535-539. https://doi.org/10.7196/samjnew.7923
g.

9. Peters $F$, van Wyk J, van Rooyen M. Intern to independent doctor: Basic surgical skills required for South African practice and interns' reports on their competence. S Afr Fam Pract 2015;57(4):261-266. https://doi.org/10.1080 20786190.2014.976954

10. Van Heerden, BB. Effectively addressing the health needs of South Africa's population: The role of health professions education in the 21st century. S Afr Med J 2012;103(1):21-22. https://doi.org/10.7196/samj.6463

11. Thomas J, Harden A. Methods for the thematic synthesis of qualitative research in systematic reviews. BMC Med Res Methodol 2008;8(1):45. https://doi.org/10.1186/1471-2288-8-45

2. Thomas J, Harden A, Oakley A, et al. Integrating qualitative research with trials in systematic reviews. BM 2004;328(7446):1010. https://doi.org/10.1136/bmj.328.7446.1010

13. Mays N, Pope C. Assessing quality in qualitative research. BMJ 2000;320(7226):50. https://doi.org/10.1136/ bmi. 320.7226 .50

14. Kuper A, Lingard L, Levinson W. Critically appraising qualitative research. BMJ 2008:337(3):a1035-a1035 https://doi.org/10.1136/bmj.a1035

15. Burch V, Van Heerden B. Are community service doctors equipped to address priority health needs in South Africa? S Afr Med J 2013;103(12):905. https://doi.org/10.7196/samj.7198

16. Scott J, Revera Morales D, McRitchie A, et al. Non-technical skills and healthcare provision in low- and middleincome countries: A systematic review. Med Educ 2016;50(4):441-455. https://doi.org/10.1111/medu. 12939

17. Tutarel O. Geographical distribution of publications in the field of medical education. BMC Med Educ 2002;2(1):1-7. https://doi.org/10.1186/1472-6920-2-3

18. Carr S, Celenza A, Lake F. Assessment of junior doctor performance: A validation study. BMC Med Educ 2013;13(1):1-6. https://doi.org/10.1186/1472-6920-13-129
19. Archer J, Norcini J, Southgate L, Heard S, Davies H. Mini-PAT (Peer Assessment Tool): A valid component of a national assessment programme in the UK? Adv Health Sci Educ 2006;13(2):181-192. https://doi.org/10.1007/ s10459-006-9033-3

20. Hicks PJ, Schumacher DJ, Benson BJ, et al. The pediatrics milestones: Conceptual framework, guiding principles and approach to development. J Grad Med Educ 2010;2(3):410-418. https://doi.org/10.4300/jgme-d-10-00126.1 21. Ten Cate O, Scheele F. Viewpoint: Competency-based postgraduate training: Can we bridge the gap between theory and clinical practice? Acad Med 2007;82(6):542-547. https://doi.org/10.1097/acm.0b013e31805559c7

22. Gardner A, Scott D, Choti M, Mansour J. Developing a comprehensive resident education evaluation systen in the era of milestone assessment. J Surg Educ 2015;72(4):618-624. https://doi.org/10.1016/j.jsurg.2014.12.007

23. Ash S. A comparison of two months versus two weeks of internship anaesthesia training. S Afr J Anaesth Analg 2009;15(1):23. https://doi.org/10.1080/22201173.2009.10872583

24. Nkabinde T, Ross A, Reid S, Nkwanyana N. Internship training adequately prepares South African medical graduates for community service - with exceptions. S Afr Med J 2013;103(12):930-934. https://doi.org/10.7196 samj.6702

25. Binnendyk J, Watling C. CanMEDS in context: A transition to residency innovation. Med Educ 2015;49(11):11501151. https://doi.org/10.1111/medu.12862

26. Davis D, Mazmanian P, Fordis M, et al. Accuracy of physician self-assessment compared with observed measures of competence. JAMA 2006;296(9):1094. https://doi.org/10.1001/jama.296.9.1094

27. McKenzie S, Burgess A, Chapman R, Mellis C. Pre-interns: Ready to perform? Clin Teach 2015;12(2):109-114 https://doi.org/10.1111/tct.1225

28. Barnsley L, Lyon P, Ralston S, et al. Clinical skills in junior medical officers: A comparison of self-reported confidence and observed competence. Med Educ 2004;38(4):358-367. https://doi.org/10.1046/j.13652923.2004.01773.x

29. Ibrahim J, MacPhail A, Chadwick L, Jeffcott S. Interns' perceptions of performance feedback. Med Educ 2014;48(4):417-429. https://doi.org/10.1046/j.1365-2923.2004.01773.x

30. D'Eon M, Trinder K. Evidence for the validity of grouped self-assessments in measuring the outcomes of educational programs. Eval Health Prof 2013; 37(4):457-469. https://doi.org/10.1177/0163278713475868

31. Burch V, Nash R, Zabow T, et al. A structured assessment of newly qualified medical graduates. Med Educ 2005;39(7):723-731. https://doi.org/10.1111/j.1365-2929.2005.02192.x

32. Kusel B, Farina Z, Aldous C. Anaesthesia training for interns at a metropolitan training complex: Does it make the grade? S Afr Fam Pract 2014:56(3):201-205. https://doi.org/10.1080/20786204.2014.936664

33. Hesketh $\mathrm{E}$, Anderson F, Bagnall G, et al. Using a $360^{\circ}$ diagnostic screening tool to provide an evidence trail of junior doctor performance throughout their first postgraduate year. Med Teach 2005;27(3):219-233. https://doi. org/10.1080/01421590500098776

34. Miller A, Archer J. Impact of workplace based assessment on doctors' education and performance: A systematic review. BMJ 2010;341:(1-6). https://doi.org/10.1136/bmj.c5064

5. Wilkinson J, Crossley J, Wragg A, et al. Implementing workplace-based assessment across the medical specialtie in the United Kingdom. Med Educ 2008;42(4):364-373. https://doi.org/10.1111/j.1365-2923.2008.03010.

36. Fletcher KE, Davis SQ, Underwood W, Mangrulkar RS, McMahon LF, Saint S. Systematic review: Effects of resident work hours on patient safety. Ann Intern Med 2004;141(11):851-857. https://doi.org/10.7326/00034819-141-11-200412070-00009

37. Erasmus N. Slaves of the state - medical internship and community service in South Africa. S Afr Med 2012;102(8):655-658. https://doi.org/10.7196/samj.5987

Accepted 15 August 2017 